\title{
Post-closure land uses - defined through a strategic land use planning approach
}

\author{
DF Pershke Pershke Consulting Pty Ltd, Australia \\ PE Elliott Pershke Consulting Pty Ltd, Australia
}

\begin{abstract}
There has been an assumption that rehabilitation should return mine sites to a natural ecosystem reflecting the pre-mining condition. This view is commonly expressed by civil action groups and is implied by the hierarchy outlined in the Western Australia (WA) Guidelines for Preparing Mine Closure Plans, which suggest that a preferred post-closure outcome is to "reinstate natural ecosystems to be as similar as possible to the original ecosystem".

While the guidelines allow for alternative land uses to be considered, there is generally limited consideration of post-mining land uses, with the default position being that the land will revert to a pre-mining land use (Western Australia Biodiversity Science Institute 2018). Although this outcome might satisfy agencies responsible for mine closure regulation, there are others that question whether this provides best value to the region; for example, East Kimberley Chamber of Commerce and Industry (2017).

This paper draws on the literature and the authors' recent experiences in working with mining companies in different regional areas of WA to illustrate:

- How techniques drawn from the land use planning industry can be used to facilitate a more systematic approach to post-closure land use planning.

- The company and regional benefits associated with an alternative approach to post-closure land use planning.

- The hurdles and challenges that these projects are facing and what has been done or needs to be done to overcome them.

- The potential benefits of a collective action approach.
\end{abstract}

We will identify areas where we have had wins in overcoming hurdles and challenges, and areas where further work or alternative approaches are required.

Keywords: land use, planning, productive use, collective action

\section{$1 \quad$ Introduction}

In Australia, there has been an assumption that rehabilitation should return mine sites to a natural ecosystem reflecting the pre-mining condition. This view is commonly expressed by civil action groups (Environmental Defenders Office of Australia 2017; Lock the Gate Alliance 2017) and is implied by the hierarchy outlined in the Western Australia (WA) Guidelines for Preparing Mine Closure Plans (Environmental Protection Authority and Department of Mines and Petroleum [EPA \& DMP] 2015). This hierarchy states that the preferred post-closure outcome is to "reinstate natural ecosystems to be as similar as possible to the original ecosystem".

While the guidelines allow for alternative land uses to be considered, there is generally limited consideration of post-mining land uses in mine closure planning, with the default position being that the land will revert to a pre-mining use (Western Australian Biodiversity Science Institute [WABSI] 2018). Although this outcome might satisfy agencies responsible for mine closure regulation, there are others that 
note the constraints that mining tenure poses to other land development opportunities (Goldfields Esperance Development Commission [GEDC] 2016) and question whether this provides best value to the region (East Kimberley Chamber of Commerce and Industry 2017). Indeed, the International Council on Mining and Metals (ICMM) Integrated Mine Closure Good Practice Guide (ICMM) (2019) notes that mined lands may be returned to pre-mining land use but that this is not always desired or possible due to alterations of the landscape and socio-economic context. For example, returning a pre-mining state may offer little future employment opportunities where the mine has created a large dependent community.

The authors posit that in WA barriers to achieving post-closure land uses that depart from the pre-mining land use include the different objectives and separate processes of government agencies regulating mine development and closure, and those responsible for economic development. Heyes et al. (2018) make similar observations and state that the current regulatory frameworks for the closure of mines focus largely on the protection of environmental values and minimisation of liabilities that may fall to governments and host communities. In WA, this manifests as a focus on safe, stable and non-polluting landforms with a bias towards achieving a self-sustaining ecosystem on closed sites. This focus has little intersection with the interests of agencies responsible for economic development.

Economic development agencies are focused on the sustainability of communities and regions, including economic development to provide jobs and projects to improve the liveability of the area and wellbeing of the population. Land occupied by mining tenure is generally not considered in local and regional land use plans for several reasons including:

- The often-articulated assumption that anything to do with land occupied by mine tenure is the responsibility of the agency responsible for regulating mining.

- The need to protect future access to potential mineral resources.

Given the separate focuses of statutes associated with the development and closure of mining projects and development of other land uses, it is not surprising that mine closure regulation does not provide guidance on the transition to an alternative sequential land use or facilitate this transition. The lack of integration between mine closure planning and regional economic development means that opportunities for achieving win-win outcomes (i.e. sites with low residual liability and a productive post-mining land use) are compromised. Murphy \& Heyes (2016) highlighted the opportunity to 'repurpose' mine sites for alternative land uses by aligning those uses with regional development strategies to provide long-term intergenerational benefits to host communities.

This paper describes a process used by the authors that leverages regional development planning to bridge the gap between traditional mine closure planning in Australia and socio-economic development. It is contended that the process can bring mutual benefits for:

- Mining companies.

- Government agencies responsible for economic development.

- Government agencies responsible for mine closure regulation.

- Communities.

- Investors and developers.

A brief overview of the approach is provided in Section 2 to provide context to the case studies presented in Section 3. Section 4 then provides a more detailed discussion of the steps in the approach and some of the key lessons learned during the case studies. The potential benefits identified, through the planning phase, are summarised in Section 5 . The benefits vary by mining company, region and site-specific context. They have yet to be tested through stakeholder consultation and project implementation, but initial dialogue has been positive. 


\section{Overview of approach}

This section provides an overview of the standard approach used in all three case studies. Further discussion of the steps and lessons learned from its use is provided in Section 4. The approach is derived from a strategic land use planning process used by the authors to inform a regional integrated transport and land use strategy for a region in Perth and comprises the following steps:

\section{Context analysis}

This is an approach commonly used by the land use planning industry to identify the key challenges and opportunities within a region to help focus regional and local development plans. It is generally summarised in the first few chapters of these plans. The use of this approach for post-closure land use planning recognises that no project exists in isolation, and the context of the project will have a large influence on the type of land uses that may be viable post-closure.

\section{Opportunity identification}

The opportunity identification (visioning) process adopted for the regional integrated transport and land use strategy recognised the interdependencies and areas of common interest that exist between various stakeholders. In the context of identifying possible post-closure land uses, the interdependencies and areas of common interest help to identify land use opportunities that provide win-win solutions for a range of stakeholders, including the mining company, regulators, landowners and community.

\section{Opportunity evaluation}

Outcomes for the mining company are the focus of traditional opportunity evaluation processes within the mining industry. The land use planning industry takes a wider view, as it is focused on defining a way forward that contributes to the greater good of the region for which it is planning. Therefore, in evaluating potential post-closure land uses, there needs to be a greater focus on the wider benefits/costs of an opportunity as this will influence support for, and viability of, opportunities.

\section{Strategic plan development}

Land use planning takes a regional approach to matching up potential land uses with areas best suited to support them. All plans cascade from one level to the next. For example, the Goldfields Esperance Regional Investment Blueprint (GEDC 2016) takes direction from the Western Australian Planning Commission's (WAPC) State Planning Strategy (WAPC 2014).

Integration of post-mining land uses with regional strategic land use plans assists in providing a pathway to build on the existing economic context, and open opportunities for the growth of new economic activity to mitigate the impact of eventual mine closure.

While post-mining concept master plans have been developed for single sites (e.g. at Alcoa's Point Henry smelter in Victoria (Alcoa 2017) and Penrith Lakes in New South Wales (Penrith Lakes 2019)), it is suggested that strategic plan development for post-mining land uses works best when applied on a regional scale, particularly where mine sites are in remote locations. This is consistent with the approach adopted for regional land use planning. The regional approach provides the greatest scope for matching multiple stakeholder/agency objectives to areas of land that have the best capability to meet those objectives (considering both physical and human capital). It also provides opportunities to consider economies of scale, use of regional infrastructure and access to markets. This approach is currently being adopted by AngloAmerican/DeBeers in the Limpopo Region of Africa using Regional Development Corridors and Spatial Development Initiatives (Anglo-American plc. 2016). 


\section{Implementation}

The process followed for the regional integrated transport and land use strategy established a common vision for the region, which would be used to guide the development and implementation of an integrated transport and land use strategy. Recently, more participatory, collaborative models of collective action (described further in Section 4.4) have evolved to facilitate the implementation of strategic plans centred around a common vision. These processes can be harnessed by mining companies to facilitate post-closure land use development.

\section{Case studies}

To date, the process outlined in Section 2 has been applied to three projects located in different regions of WA. This section provides an overview of the three case studies and some observations on how the postclosure land use planning methodology has been applied. All the case studies are ongoing works in progress.

\subsection{Case study 1: Evolution Mining, Norton Gold Fields, Northern Star Resources - Goldfields, Western Australia}

Evolution Mining, Norton Gold Fields and Northern Star Resources have reasonably proximal mining and pastoral leases and have collaborated to formulate a potential concept land use master plan for the area occupied by their leases. The regional approach and inclusion of pastoral leases has enabled the companies to develop an overall land use concept plan that provides improved:

- Land asset value of the underlying pastoral leases post-closure.

- Socio-economic value for the local region and communities.

- Overall environmental outcomes across the leases.

The plan considers land uses that might be implemented on legacy mining areas to provide for active management of the sites post-closure. For example, some sites are located close to public roads and facilities. While standard abandonment bunding can and will be put in place, third-party access risk could be further reduced through active control provided as part of a post-closure land use.

In exploring land capability, interdependencies and areas of common interest, it was identified that implementation of a carbon farming project on poor pastoral land could potentially provide a stream of revenue for the pastoral lessee; a portion of which could be invested in improvements to pastoral infrastructure that could include facilities for tourists or visitors. Some of the closed mine sites could be developed into tourist attractions or recreational facilities, which could enhance the tourism business of the pastoral lessee and provide jobs for local tourism operators. The implementation of a carbon farming project on a pastoral lease has the potential co-benefit of improving biodiversity.

\subsection{Case study 2: South32 - southwest of Western Australia}

South32's Worsley operation is a long-lived bauxite/alumina operation in the southwest of WA, which holds several freehold properties. The freehold properties are used for mining, access routes or for buffer land between mining activities and local communities. The study was conducted as part of South32's Intelligent Land Management Program and focused on both post-closure land uses and land uses that can be implemented in the short to medium term on buffer land that is not likely to be mined. One of the interesting outcomes of this study was the potential for conflict between different stakeholder objectives for land in the region.

The freehold land owned by the company comprises agricultural land and native vegetation. At first glance, one might assume that planting of agricultural land for biodiversity provides the best value land use. However, a closer look at the regional context showed that further development and diversification of 
agriculture was a key regional development strategy and that other regional aspirations included development of tourism. The company is currently exploring how it may use its land to balance biodiversity, agricultural production and tourism objectives. One possible avenue being explored is whether the implementation of regenerative agriculture can maintain agricultural productivity (and local economic benefit) while also improving biodiversity outcomes and other environmental values such as water quality. Once the feasibility of this approach has been established, the company could consider how the initiative may be leveraged to provide further socio-economic value to the region. Avenues that could be explored include possible links to research, education and tourism.

\subsection{Case study 3: BHP - eastern and central Pilbara, Western Australia}

BHP is a long-lived mining operation in the Pilbara with multiple sites across a wide regional area. The company is also the lessee of three pastoral leases. The context analysis identified that key regional strategies, such as those presented in the Pilbara Regional Investment Blueprint (Pilbara Development Commission 2017), included, among other things, aspirations for:

- Tourism focused around the Warlu Way.

- Aquaculture, including algal culture.

- Renewable energy, including long distance transmission of solar energy to markets via high voltage direct current interconnectors.

- Irrigated agriculture.

- Regional approach to biodiversity conservation.

We also found that there were several existing BHP initiatives that could be aligned with these regional planning aspirations and a post-mining land use. Some interesting examples are summarised in Table 1 along with thoughts of how they could potentially relate to post-closure land use planning. A number of the initiatives in Table 1 include research into pre-commercial technologies but, given the long-lived nature of BHP's operations, the technologies may be feasible by the time mining operations cease.

An opportunity identification workshop was held with a range of stakeholders from different technical backgrounds within BHP. The workshop drew on the context analysis and used a scenario planning process to help participants envisage a range of different futures and the land uses that might be applicable in these futures. The process was used to promote divergent thinking. It also enabled those opportunities that would be potentially viable in most scenarios to be distinguished.

The next steps in the process include consultation with key stakeholders and development of a strategic land use plan. One possible approach that could be explored is the use of a collective action process. The approach lends itself to the development and implementation of long-term strategic land use plans. BHP is already working with industry, government and community representatives via the Hedland Collective to develop a common approach to maximising the benefits from resource sector operations in Port Hedland (BHP 2018). The goals of this initiative are to:

- Strengthen local employment, training and business development.

- Coordinate social services to ensure support for all community members.

- Build and communicate community vibrancy and culture. 
Table 1 BHP initiatives and possible links to post-closure land use planning

\begin{tabular}{|c|c|}
\hline BHP initiative & $\begin{array}{l}\text { Questions that could be explored in post-closure land use } \\
\text { planning }\end{array}$ \\
\hline \multirow{2}{*}{$\begin{array}{l}\text { BHP has an Indigenous Business } \\
\text { Support Program that is aimed at aiding } \\
\text { the start-up, growth and expansion of } \\
\text { Pilbara Traditional Owner businesses in } \\
\text { Western Australia (BHP 2017). }\end{array}$} & $\begin{array}{l}\text { Could the development or management of tourism } \\
\text { attractions or other industries, on or adjacent to closed sites, } \\
\text { be an area of interest to Traditional Owners? }\end{array}$ \\
\hline & $\begin{array}{l}\text { Could the current business support program be used to help } \\
\text { build capacity to service such an enterprise? }\end{array}$ \\
\hline $\begin{array}{l}\text { BHP sponsors several ephemeral } \\
\text { sporting and arts events. }\end{array}$ & $\begin{array}{l}\text { Could these events be used to raise awareness of, and create } \\
\text { a market for, tourist attractions located on closed mine sites? }\end{array}$ \\
\hline \multirow{2}{*}{$\begin{array}{l}\text { Research is being conducted in the } \\
\text { United States on the potential to use } \\
\text { algae to remediate contamination and } \\
\text { then use the algae in the production of } \\
\text { biofuels. }\end{array}$} & $\begin{array}{l}\text { Could footprints disturbed by mining be used to produce } \\
\text { biofuels from algae if a commercially viable approach to } \\
\text { production was developed? }\end{array}$ \\
\hline & $\begin{array}{l}\text { Could water from pit lakes be abstracted and used in algal } \\
\text { production? }\end{array}$ \\
\hline $\begin{array}{l}\text { BHP is investigating direct air capture of } \\
\text { carbon dioxide }\left(\mathrm{CO}_{2}\right) \text {. }\end{array}$ & $\begin{array}{l}\mathrm{CO}_{2} \text { is required for production of some algae. Could } \\
\text { production of algae be an opportunity for offsetting carbon } \\
\text { emissions as a co-benefit? }\end{array}$ \\
\hline \multirow{2}{*}{$\begin{array}{l}\text { BHP is investigating several renewable } \\
\text { energy applications including green } \\
\text { hydrogen. Green hydrogen is at a pre- } \\
\text { commercial stage. }\end{array}$} & $\begin{array}{l}\text { Could a closed remote mine site away from population } \\
\text { centres with good access to rail and ports be a potential } \\
\text { location for green hydrogen production? }\end{array}$ \\
\hline & $\begin{array}{l}\text { Hydrogen production requires water. Could residual mine } \\
\text { voids play a role in storing/supplying this water? }\end{array}$ \\
\hline
\end{tabular}

\section{Discussion}

The steps in the process outlined in Section 2 are described in further detail in Sections 4.1 to 4.4 along with a summary of some of the general observations we have made from implementing them for different projects.

\subsection{Context analysis}

Establishing the context for a region enables the mining company and other key stakeholders to be fully aware of the diverse and sometimes disparate drivers for land use planning and development in a region. The context analysis goes beyond the traditional knowledge base required in a mine closure plan and draws on a wider set of information, which generally falls into five domains:

- Environmental.

- Social.

- Economic.

- Political.

- Technological. 
The context analysis asks, "what is happening in the region across each of these domains and how will this affect land use patterns and development?". The context analysis comprises three key elements:

- External context review (Section 4.1.1).

- Internal context review (Section 4.1.2).

- Analysis (Section 4.1.3).

\subsubsection{External context review}

The external context review consists of an examination of those factors that are outside the direct control of a mining company and involves a study of the factors that drive the development of, or land uses within, a region. It involves desk-top research across the domains outlined above. Verification of this information may be undertaken through targeted engagement. In addition to local and regional strategic planning documents, types of information incorporated into the review may include:

- Biodiversity and natural resource management plans.

- Traditional Owner plans.

- Agricultural and pastoral analyses and plans.

- Analyses of the availability of energy and gas.

- Reports on the impacts of climate change and climate change policy on the region.

- Assessments of regional water availability and quality.

- Tourism and arts strategies and plans.

- Underlying tenure and associated constraints and opportunities.

\subsubsection{Internal context review}

During the presented case studies, an understanding of the internal context of a mining company and the sites they operate was found to be of value. This internal context enabled the identification of:

- Closure issues that need to be managed in specific locations (e.g. pit lakes, acid metalliferous drainage, eroding landforms). In WA, this information is typically available in mine closure plans.

- Future mine plans that might enable or constrain a land use opportunity.

- Other issues of strategic importance to a mining company that may have an interaction with closure planning.

- Existing activities that could be integrated with closure planning to enhance closure outcomes and a company's contribution to the region.

The value of this approach was highlighted by the BHP case study that uncovered a range of activities that are already occurring within the organisation, which could be harnessed to facilitate the development of a post-closure land use (refer to Table 1).

The review has also enabled the identification of projects that could serve to address various strategic issues for companies (e.g. reduce or offset carbon emissions) while also providing benefit to the region (e.g. renewable energy project, carbon farming).

\subsubsection{Analysis}

The context analysis involves:

- Identifying areas of common interest as well as potential conflicts from the information collected during the internal and external reviews. Utilisation of this knowledge in the 
opportunity identification and evaluation steps has helped select land use opportunities that have win-win-win outcomes for mining companies, local communities/regions and regulators. In particular, it helps encourage ideas for land uses that can assist in managing or further reducing closure risks that may only manifest in the long-term or that are associated with legacy sites.

- Conducting a spatial analysis. Useful datasets include:

- Analysis of mining assets and potential land use constraints and impacts (e.g. power and water infrastructure, pit lakes, tailings storage facilities, waste rock dumps, potential for poor water quality or seepage, high risk of third-party access, erodible materials).

- Natural capital and natural resources (e.g. biodiversity conservation areas, areas of good quality native vegetation, water).

- Land capability, suitability and condition for pastoral/agricultural use including potential for carbon sequestration.

- Existing tourism sites and defined tourism trails/routes.

- Existing third-party infrastructure including roads, rail, gas, water, power, pastoral infrastructure.

This information provides a basic understanding of land capability to support different land uses within the region.

\subsection{Opportunity identification}

The land use opportunity identification process draws on the context analysis and can encompass ideas provided by stakeholders. It provides the opportunity to create divergent thinking about what might be possible for a region. In one of our projects, ideas were sought from key external stakeholders (such as local and regional government agencies and natural resource management groups) as part of the opportunity identification process. In other projects, the process has relied on documented sources of information, with stakeholder consultation planned for a later stage.

Experience so far has been that early stakeholder consultation did not provide much information on possible opportunities that were not already identified through our review of documentation. In many cases, stakeholders were looking for ideas from the company as to what land uses could be implemented. This has led the authors to the view that perhaps presentation of some ideas to stakeholders as the basis for discussion at later stages of the project would be a better approach. It is, therefore, proposed to engage with stakeholders at the strategic plan development stage as part of a collective action planning process (see Section 4.4 for further information on this approach).

In all of the projects undertaken, opportunities have been considered for use of nearby land, owned or leased by the mining companies that is not likely to be used for mining, as well as potential post-closure uses of land occupied by mining leases. This has enabled consideration of opportunities for land uses that can be implemented ahead of the cessation of production to:

- Address current strategic issues for mining companies such as meeting biodiversity offset requirements or carbon reduction commitments.

- Build capacity of local communities in preparation for a time when the mining company no longer has a presence in the region.

- Contribute to economic development of the region and the development of industries that may be able to support the population post-mining. Facilitating the early development of industries that do not necessarily rely on mining provides an avenue for maintaining the economic infrastructure and human capital necessary to support a post-mining land use in a remote region following cessation of mining activities. 
The regional approach has also enabled consideration of where expenditure across a portfolio of land will achieve the best outcomes to address different objectives. Key learnings are that the regional approach can enable the stated objectives of multiple stakeholders to be met, and that different land use opportunities can be crafted to deliver a range of co-benefits if considered in the light of the full context analysis.

\subsection{Opportunity evaluation}

The opportunity evaluation processes appropriate to different projects are dependent on the stage of a mine's life. For example, in a long-lived operation like BHP, the post-closure land use evaluation process may only proceed as far as identifying a number of possible land uses that might be supported by different mining areas. This would include formulation of criteria to describe the land capability/performance requirements of the potential land use (e.g. the area needs to be flat, pit voids need to be designed to capture and contain water) and an analysis of the capability of a given site to meet those criteria. This might include:

- The physical capability of the land disturbed by mining operations and the area surrounding it (e.g. soil types, water availability, topography).

- Proximity to infrastructure such as roads, power, water, gas.

- Proximity to other similar uses of land (e.g. tourism sites, agriculture, conservation).

Compatible land uses can be grouped as a further refinement. An output could be as shown in Figure 1.

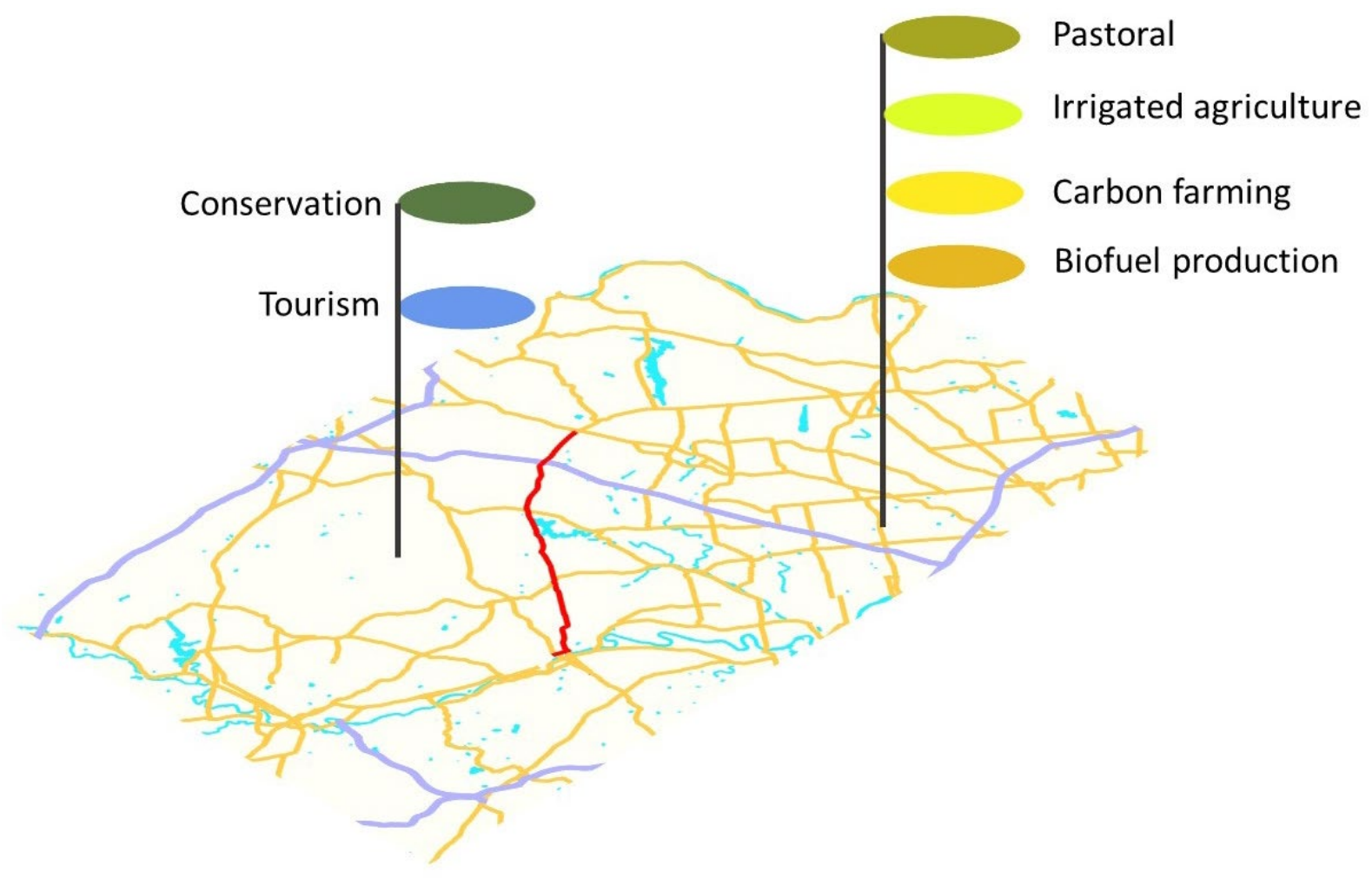

Figure 1 Output of high-level opportunity evaluation process for long-lived mining operation for illustrative purposes only

Detailed evaluation of land uses would be difficult for long-lived operations that are far from closure, as the economic viability of a land use will change over time as the regional context changes. However, in some instances, decisions will need to be made early about whether a landform design or closure strategy will be changed to enable a particular post-closure land use to occur, or whether this land use will be discounted from future consideration. For example, where a land use relies on residual mine voids and pit lakes to supply water, the potential risks and likely feasibility and benefits of this land use would need to be 
assessed prior to taking a decision as to whether to backfill the mine. Such decisions may be required at a time where the economic viability of a land use is still not well understood.

At this early stage of planning, a multi-criteria assessment can be used to screen land uses that a company may wish to pursue in the future. A range of criteria derived from the context analysis have been used for each project. They generally relate to:

- Value of the land use to the mining company, investors and underlying landowners or managers. From a mining company perspective, this value can include contribution to achievement of strategic sustainability objectives.

- Potential for the land use to reduce residual liability to the company and the state.

- Potential for improvement in environmental values.

- Alignment with regional initiatives.

- Contribution to positive socio-economic outcomes.

- Commercial viability including consideration of maturity of technology.

A program of work to investigate the implications of mine closure designs required by various post-closure land uses can help to ensure that there is appropriate technical information available to inform technical risk and benefit assessments at the time that decisions need to be made. This program of work needs to be guided by a clear articulation of the mine closure design implications for each land use and the time frame in which key decisions would need to be made.

A further input to the evaluation of long-lived mining operations may be a scenario analysis that considers possible alternative futures for a region and identifies those land uses that might be viable across multiple futures (see case study in Section 3.3).

For opportunities that may be implemented now, or for shorter lived mining operations, normal capital project evaluation processes (i.e. concept design/pre-feasibility/feasibility/detailed design) would apply.

\subsection{Strategic plan development and implementation}

The opportunity evaluation process is likely to provide a range of different opportunities that could be implemented in various locations (both mining and other adjacent areas) over different timescales.

It is not necessarily the role of a mining company to implement the land use opportunities identified through the opportunity identification and evaluation process, although some may choose to have a role in this to service ongoing operations (e.g. in the case of power supply) or post-closure management (e.g. treatment of contamination). However, the plan can provide long-term direction for social investment initiatives and enables engagement with future investors and developers. For example, if tourism is a strong focus of a post-closure land use plan, then social investments in education could be linked to skills such as customer service, tourism marketing and business development. The plan can also assist regional economic development agencies and potential investors in identifying where and when they might invest.

Collective action planning processes lend themselves very well to the development and implementation of strategic land use plans. During the case studies it was found that there were a range of internal and external stakeholders working on various projects that could contribute to the overall development of land uses within a region (refer to Table 1 in Section 3.3 as an example). The concept of collective action is that these diverse stakeholders/organisations align to a common goal or vision and agree to track progress in the same way so that results can be consistently measured (FSG n.d.).

Within the framework of the common goals, each organisation/stakeholder then delivers on those programs or activities that are part of its mandate and for which it is best suited (FSG n.d.). For example, where jobs for the region are the common goal, agencies responsible for education would deliver on educational outcomes, but these programs would align with the overall vision established by the collective. 
The collective action process for delivering a strategic land use plan could potentially draw in:

- Regional and local planning agencies.

- Regulators.

- Underlying landholders including government and private entities.

- Conservation agencies and not-for-profit groups.

- Aboriginal groups.

- Education agencies and not-for-profit groups.

- Mining company representatives from a range of areas including mine closure planning, social performance/investment, environment and research.

The aim of the strategic plan would be to facilitate the development of other land uses/businesses while mining is still occurring so that these have an opportunity to establish and grow over time into businesses that will support the region following cessation of mining activities. This transition is shown simplistically in Figure 2.

\section{Proportion of jobs - mining activities}

\section{Figure 2 Land use transition concept}

However, there are still a number of challenges that will need to be worked through to facilitate this smooth transition. These include mechanisms for:

- Enabling mining operations and new land uses to co-exist. To achieve a smooth transition, it will be critical to enable alternative land uses to establish early so that they can grow to support the region as mining jobs reduce through the closure and post-closure periods. For some land uses, this co-existence can be reasonably easily achieved such as those that are permitted under pastoral leases. For other land uses, this may be more problematic and may involve a change in underlying tenure. There are also a range of business issues that must be worked through by both the mining company and the company investing in the new land use. These include contractual arrangements that spell out the rights of each party should:

- The mining company need to access the area occupied by the third-party at a later time.

- The third-party cease operations.

- Transfer of liability.

- Recognising that all land uses are temporary and providing contingencies for continuing the ongoing post-closure management of a closed mine should a third-party land use fail.

\section{Conclusion}

In summary, the approach outlined in this paper can bridge the gap between traditional mine closure planning and regional socio-economic development planning in Australia. It enables post-closure land use planning to align with regional land use plans and encourages the identification of land use opportunities that have win-win-win outcomes for mining companies, local communities/regions and regulators (refer to Appendix for a summary of potential benefits). 
The approach blends the consideration of internal and external factors to optimise the management of closure risks/long-term liabilities and provides a contribution to the transition to an alternative economic activity post-closure.

Furthermore, the case studies presented indicate that a regional approach provides the greatest scope for matching multiple stakeholder/agency objectives to areas of land that have the best capability (which can include physical and human capital) to meet those objectives. Including nearby unmined land owned or leased by the mining companies into the assessment, as well as land disturbed by mining, enables identification of opportunities that could be implemented now to facilitate a smooth transition to a postclosure future for the region and enhance overall socio-economic and environmental outcomes.

The development of a strategic land use plan that aligns with regional plans can assist in providing longterm direction for company social investment initiatives as well as assist regional economic development agencies and potential investors in identifying where and when they might invest.

In long-lived operations, it might be difficult to make final decisions on post-closure land uses due to the uncertainties about the future regional context and economic viability of different uses. However, a strategic regional plan can show areas that have the capability to support several different land uses. Collective action planning processes can then be used as a vehicle to further develop and implement plans in a way that enables alternative industries to grow over time. Unmined land owned or leased by the mining companies can be a valuable asset in facilitating this early growth.

There are still a number of challenges that will need to be worked through to facilitate a transition to a post-mining future. These include mechanisms for:

- Enabling mining operations and new land uses to co-exist to enable a gradual transition from mining to other economic activities.

- Transferring liability.

- Recognising that all land uses are temporary and providing contingencies for continuing the ongoing post-closure management of a closed mine should a third-party land use fail.

\section{Acknowledgement}

The authors would like to thank the companies involved in the case studies (Evolution Mining, Norton Gold Fields, Northern Star Resources, South32 and BHP) for coming on the journey with us and allowing us to publish their case studies in this paper. In particular, we would like to thank the company staff who have provided their time, knowledge and guidance in assisting in validating the process and providing input to the identification of realistic land use alternatives. 


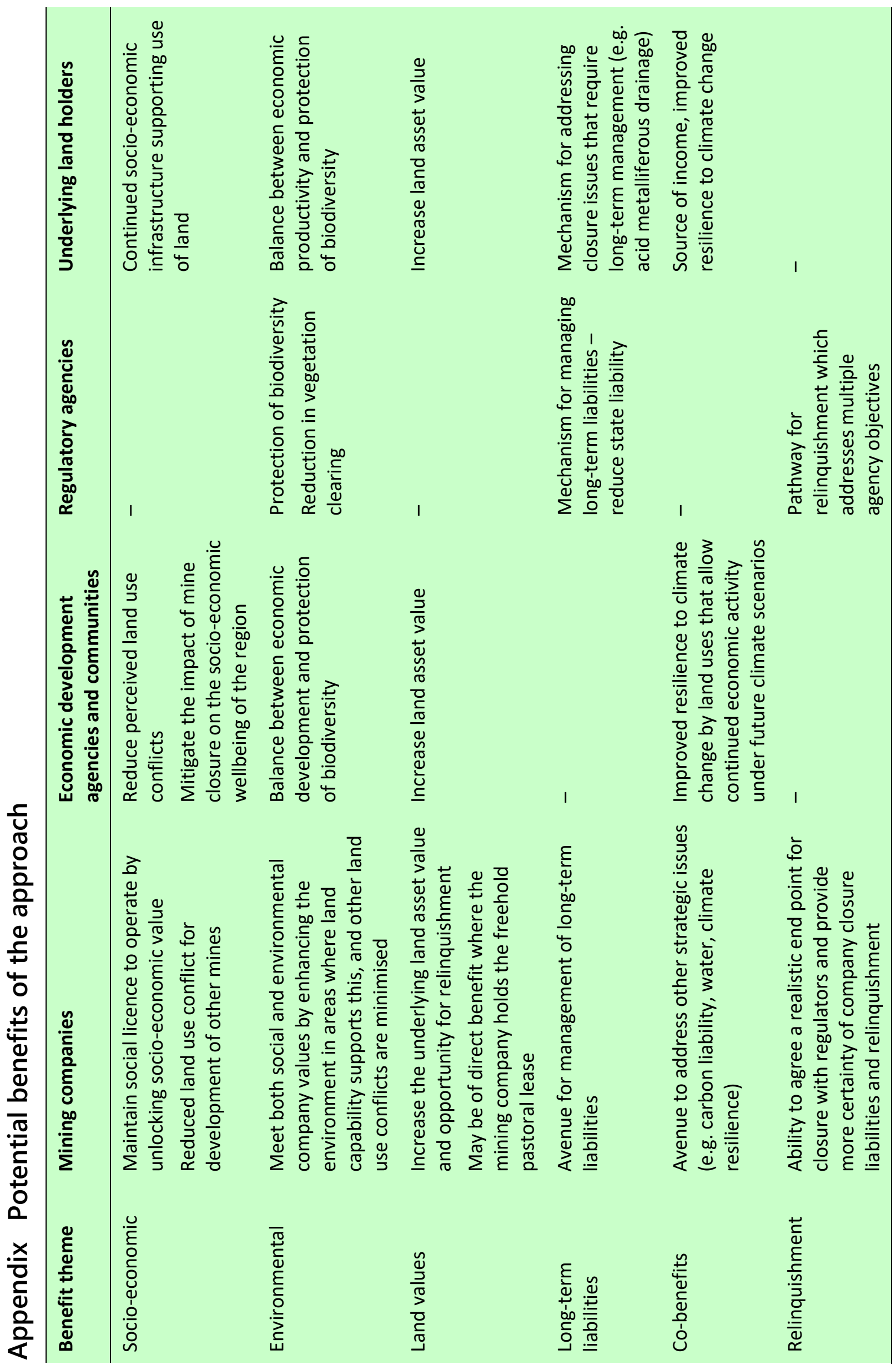




\section{References}

Alcoa 2017, Point Henry 575, viewed 28 June 2017, https://engage-pointhenry.alcoa.com.au

Anglo-American plc. 2016, Sustainability Report, viewed 22 May 2019, https://www.angloamerican.com/ /media/Files/A/AngloAmerican-PLC-V2/documents/annual-reporting-2016/downloads/sustainability-report-2016.pdf

BHP 2018, Hedland Collective: A collaborative focus on community enhancement, viewed March 2019. https://www.bhp.com/community/case-studies/2018/09/hedland-collective-a-collaborative-focus-on-communityenhancement

BHP 2017, Reconciliation Action Plan 2017-2020, viewed March 2019. https://www.bhp.com//media/documents/ourapproach/operatingwithintegrity/indigenouspeoples/180717_bhpreconciliationactionplan.pdf?la=e $\mathrm{n}$

East Kimberly Chamber of Commerce and Industry 2017, Submission to the Inquiry into the rehabilitation of mining and resources projects as it relates to Commonwealth responsibilities.

Environmental Defenders Office of Australia 2017, Inquiry into the rehabilitation of mining and resources projects as it relates to Commonwealth responsibilities. Canberra, viewed March 2019, https://www.aph.gov.au/Parliamentary_Business/ Committees/Senate/Environment_and_Communications/MiningandResources/Submissions

Environmental Protection Authority and Department of Mines and Petroleum 2015, Guidelines for Preparing Mine Closure Plans, Government of Western Australia, Perth.

FSG n.d., Tackling complex problems with collective impact, viewed March 2019, https://www.fsg.org/areas-of-focus/collectiveimpact

Goldfields Esperance Development Commission 2016, Goldfields-Esperance Regional Investment Blueprint. A plan for 2050, viewed 22 June 2019, http://www.gedc.wa.gov.au/our-region/regional-plans/goldfields-esperance-regional-investment-blueprint

Heyes, J, Murphy, D, Foster, S \& White, S 2018, 'What Comes After Mining? How Regulatory Frameworks Can Enable Creativity', in $\mathrm{C}$ Drebenstedt, F von Biscmarck, A Fourie \& M Tibbett (eds), Proceedings of the 12th International Conference on Mine Closure, Technical University Bergakademie Freiberg, Leipzig, pp. 171-179.

International Council on Mining and Metals 2019, Integrated Mine Closure Good Practice Guide, 2nd edn, viewed 22 June 2019 https://guidance.miningwithprinciples.com/integrated-mine-closure-good-practice-guide/

Lock the Gate Alliance 2017, Rehabilitation of Mining Resources Projects as it relates to Commonwealth Responsibilities, viewed March 2019, https://www.aph.gov.au/Parliamentary_Business/Committees/Senate/Environment_and_Communications/ MiningandResources/Submissions

Murphy, D \& Heyes, J 2016, Mine Closure - are we using the right drivers? AusIMM Bulletin October 2016, viewed March 2019, https://www.ausimmbulletin.com/feature/mine-closure-are-we-using-the-right-drivers/

Penrith Lakes 2019, A Destination to Live, Work, Shop, Play and Retreat into Nature, viewed March 2019, https://www.penrithlakes.com.au/home/?filter=filter_news_3352_0:page_index:0

Pilbara Development Commission 2017, Pilbara Regional Investment Blueprint, viewed March 2019, https://www.pdc.wa.gov.au/our-focus/pilbara-blueprint

Western Australia Biodiversity Science Institute 2018, Industry Interviews and Survey, Presentation for Western Australia Biodiversity Science Institute Completion Criteria Stakeholder Workshop.

Western Australia Planning Commission 2014, State Planning Strategy 2050. Government of Western Australia, Department of Planning on behalf of Western Australian Planning Commission, Perth. 